\title{
Potential Next-Generation Probiotics Isolated from Romaine Lettuce (Lactuca sativa L. var. longifolia) Fermented Brine
}

\author{
T E Tallei ${ }^{1, *}$, Fatimawali ${ }^{2}$, A M Sumual ${ }^{2}, \mathrm{M} \mathrm{A} \mathrm{Gani}^{2}$, G A V Pollo ${ }^{1}$, A A Adam ${ }^{3}$ \\ and J J Pelealu ${ }^{1}$
}

\author{
${ }^{1}$ Department of Biology, Faculty of Mathematics and Natural Sciences, University of Sam Ratulangi, Manado, \\ Indonesia \\ ${ }^{2}$ Pharmacy Study Program, Department of Chemistry, Faculty of Mathematics and Natural Sciences, University of \\ Sam Ratulangi, Manado, Indonesia \\ ${ }^{3}$ Dentistry Study Program, Faculty of Medicine, Sam Ratulangi University, Manado, Indonesia \\ *Corresponding author.Email: trina_tallei@unsrat.ac.id
}

\begin{abstract}
Nowadays, the search for potential probiotics from lactic acid bacteria continues to develop exclusively for pharmaceutical applications. This study aimed at evaluating the potency of lactic acid bacteria (LAB) isolated from fermented brine of romaine lettuce as next-generation probiotics. The study began with romaine lettuce fermentation in a $10 \%$ salt solution for four days at room temperature in the dark. The LAB from the fermentation liquid were grown on MRS agar supplemented with $\mathrm{CaCo}_{3}$ then purified. Purified colonies were identified using Gram-staining, catalase test, and 16S rRNA gene marker, and tested for their ability to be developed as the next-generation probiotics which included the following criteria: antibacterial activity, cholesterol assimilation, and their survival at $\mathrm{pH} 3$. The cholesterol- lowering ability was evaluated by incubating the bacteria in MRS agar supplemented with $0.5 \%$ taurodeoxycholic acid (TDCA). Well diffusion method was used to assess the antibacterial activity. Their ability to withstand acid environment at $\mathrm{pH} 3$ was also evaluated. This study showed that all isolates (AS1, AS2, AS3, and AS4) survived at $\mathrm{pH} 3$ for 2 hours and grew until the fifth day. Isolates AS2, AS3, and AS4 inhibited the growth of Staphylococcus aureus, while AS1, AS3, and AS4 inhibited the growth of Escherihia coli. All isolates had the ability to lower cholesterol. Isolate AS3 was molecularly identified as Enterococcus faecium. This isolate was chosen to be identified as it showed the best characteristics among all the isolates tested. We concluded that AS3 can be further developed as next-generation probiotic.
\end{abstract}

Keywords: Enterococcus faecium, next-generation probiotics, romaine lettuce, antibacterial, cholesterollowering, acid-resistant.

\section{INTRODUCTION}

Fermentation has been one of the most ancient forms of food preservation that is still widely used to extend the period of food storage [1]. Common fermentation practices in food preservation include drying and salting [2]. During the fermentation process, there will be a shift in the microbial community because carbohydrates and other macromolecules are converted into organic acids by lactic acid bacteria (LAB) under anaerobic conditions. Besides producing organic acids, LAB also secrete various antimicrobial substances such as hydrogen peroxide and bacteriocins, which inhibit the growth of foodborne pathogens [3]. Some LAB have emerged as the next-generation probiotics because of their therapeutic abilities. Traditional probiotics generally exhibit ameliorative effects, while nextgeneration probiotics (NGP) have been shown to have 
preventive capabilities of several diseases and therapeutics [4].

Probiotics are live organisms which, when consumed in sufficient quantities, confer a health benefit on the host [5]. Also, probiotics can survive in low $\mathrm{pH}$ conditions, which makes them able to pass through the stomach, where most pathogens do not survive [6, 7]. Daily intake of probiotics has been proven to effectively lower plasma cholesterol levels [8]. The effective dose to lower cholesterol level in 14 days is $4 \times 10^{8} \mathrm{CFU} / \mathrm{ml}$ per day [9]. The benefit of NGP among others are the production of antibacterial [10, 11], antioxidant [12, 13], anti-inflammatory, neuromodulatory [14], antitumor [15, 16], compounds, alleviating irritable bowel syndrome, bowel diseases, and colon cancer [17, 18], as well as cholesterol lowering ability by producing bile salt hydrolase [19, 20].

In addition to being obtained from fermented dairy products and fruits, LAB can also be isolated from vegetable fermentation. Traditional fermented vegetables which are consumed in various parts of Asian subcontinent include Burong mustasa (pickled mustard greens Brassica juncea), Dakguadong (fermented mustard leaves), Dhamuoi (fermented cabbage Brassica oleracea var. capitata), Gundruk (fermented mixed leafy vegetables), Kimchi (fermented Chinese cabbage Brassica rapa subsp. Pekinensis), Paksian-dong (fermented African cabbage Gynandropsis pentaphylla), Sauerkraut (fermented cabbage), Sayur asin (fermented mustard greens), and Yan-tsai-shin (fermented stem of broccoli Brassica oleracea var. Italica). The LAB produced by these fermented vegetables, among others are from the genera of Lactobacillus, Pediococcus, Leuconostoc, Weissella, Enterococcus, and Lactococcus [21, 22]. A study on various kinds of kimchi, including lettuce kimchi showed that the resulting $\mathrm{LAB}$ seemed to have originated from endogenous microflora of the vegetable raw materials [23].

Various kinda of lettuces are eaten raw, and most are mixed as a salad ingredient. One type of lettuce that is a favorite in mixed-salad is Romaine lettuce (Lactuca sativa L. var. longifolia). The leaves are rosette-shaped and reach a height of 10 to $15 \mathrm{~cm}$, and stronger than other varieties of lettuces leaves. The lettuce in mixedsalad is usually not fermented. Based on experience, fermentation of romaine lettuce in a salt solution provides a unique flavor while maintaining a crispy lettuce texture. This study aimed to isolate and identify the next potential generation probiotics of lettuce fermentation products, which have the characteristics of antibacterial, cholesterol-lowering, and acid resistance.

\section{MATERIAL AND METHODS}

\subsection{Sample Preparation and Fermentation}

The Romaine lettuces were obtained from a local hydroponic farm. The leaves were cut out from the root. The whole leaves were put into fermentation containers, and the weights made of glass were placed on the leaves to prevent them from floating. A $10 \%$ salt solution was poured into the containers until the leaves were completely submerged. The containers were closed tightly and stored in the dark at room temperature for four days. The containers were designed to remove $\mathrm{CO}_{2}$ but did not allow $\mathrm{O}_{2}$ to enter. The fermented brine containing $\mathrm{LAB}$ was used for further analysis.

\subsection{Isolation of Lactic Acid Bacteria}

The BAL isolation process was conducted according to previous research [24]. The fermented brine was diluted up to $10^{-5}$. Two hundred microliters of serially diluted samples were plated on de Man, Rogosa, and Sharpe (MRS) agar and incubated at $37^{\circ} \mathrm{C}$ for 48 hours. Colonies that appeared different morphologically, which produced clear zones around them, were isolated and purified. The isolated bacteria were verified as LAB by Gram staining and catalase test. These verified bacteria were transferred to a slant agar and also NB medium containing $30 \%$ glycerol and stored at $-20^{\circ} \mathrm{C}$ for further use.

\subsection{Acid Endurance Test}

The acid endurance of LAB was determined by using a growth medium (Nutrient Broth/NB) with $\mathrm{pH} 3$. The $\mathrm{pH}$ was adjusted with $1 \mathrm{~N} \mathrm{HCl} \mathrm{[25].} \mathrm{Briefly,} \mathrm{the}$ isolates were incubated in $1 \mathrm{ml}$ of $\mathrm{NB}$ for 24 hours at $37^{\circ} \mathrm{C}$. After 24 hours, the $\mathrm{pH}$ of the media was adjusted to 3 by dropping $1 \mathrm{~N} \mathrm{HCl}$. As soon as the $\mathrm{pH}$ was adjusted, $200 \mu \mathrm{l}$ of the bacterial solution was spread on MRS agar, and incubated at $37^{\circ} \mathrm{C}$. The rest of bacterial solutions were incubated for 3 hours. At each hour, 200 $\mu 1$ of the bacterial solution was stocked and grown on MRS agar at $37^{\circ} \mathrm{C}$. The media were incubated for 5 days, and bacterial growth was observed every day.

\subsection{Evaluation of Antimicrobial Activity}

The antimicrobial activity of LAB against indicator strains was tested using the agar well diffusion assay [25]. Two hundred microliters of an overnight culture of indicator strains (Escherichia coli (Migula) Castellani and Chalmers (ATCC $\left(25922^{\mathrm{TM}}\right.$ ) and Staphylococcus aureus subsp. aureus Rosenbach (ATCC® 25923 ${ }^{\mathrm{TM}}$ )) containing approximately $10^{6}$ cells $/ \mathrm{ml}$ were used for this purpose. The LAB were grown in NB for 24 hours at $37^{\circ} \mathrm{C}$ then incubated (heat-killed) at $60^{\circ} \mathrm{C}$ for 2 hours in thermo-block, and subsequently centrifuged $(10,000 \mathrm{~g}$, $10 \mathrm{~min}$ ) to prepare cell-free supernatants (CFS). The indicator bacterial strains were spread on nutrient agar 
media, which had 5-mm-deep wells. About $100 \mu \mathrm{l}$ of each CFS was poured into well. The plates were subsequently incubated for 24 hours at $37^{\circ} \mathrm{C}$. The inhibitory zones of the isolates were checked after 48 hours. Fifty $\mu \mathrm{g} / \mathrm{ml}$ 1-cyclopropyl-6-fluoro-1,4-dihydro4-oxo-7-(1-piperazinyl)-3-quinolinecarboxylic acid was used as positive control and sterile $\mathrm{dH}_{2} \mathrm{O}$ as negative control. Inhibition zone diameter was measured. The LAB that produced clear zones $<11 \mathrm{~mm}, 11-16 \mathrm{~mm}, 17-$ $22 \mathrm{~mm}$ and $>23 \mathrm{~mm}$, were classified as negative (-), mild $(+)$, strong $(++)$, and very strong $(+++)$ inhibitors, respectively [27].

\subsection{Cholesterol-lowering Assay}

Two hundreds mililiter of overnight LAB cultures on NB were spread onto MRS agar supplemented with $0.5 \%$ taurodeoxycholic acid (TDCA). Taurodeoxycholic acid is a bile salt formed in the liver by conjugation of deoxycholate with taurine, usually as the sodium salt.

Table 1. The endurance results of isolates AS 1, AS2, AS3 and AS4 at pH 3

\begin{tabular}{|c|c|c|c|c|c|c|}
\hline \multirow[b]{2}{*}{ Time of incubation in $\mathrm{pH} 3$} & \multirow[b]{2}{*}{ Isolate } & \multicolumn{4}{|c|}{ Duration of Observation } & \multirow[b]{2}{*}{ Day 5} \\
\hline & & Day 1 & Day 2 & Day 3 & Day 4 & \\
\hline \multirow[t]{4}{*}{ Control (without $\mathrm{HCl}$ ) } & AS1 & +++ & +++ & +++ & +++ & +++ \\
\hline & $\mathrm{AS} 2$ & +++ & +++ & +++ & +++ & +++ \\
\hline & AS3 & +++ & +++ & +++ & +++ & +++ \\
\hline & $\mathrm{AS} 4$ & +++ & +++ & +++ & +++ & +++ \\
\hline \multirow[t]{4}{*}{0 hour } & AS 1 & - & + & + & ++ & ++ \\
\hline & $\mathrm{AS} 2$ & - & - & + & ++ & ++ \\
\hline & AS3 & - & - & - & ++ & ++ \\
\hline & $\mathrm{AS} 4$ & + & + & ++ & ++ & ++ \\
\hline \multirow[t]{4}{*}{1 hour } & AS1 & - & - & + & + & ++ \\
\hline & $\mathrm{AS} 2$ & - & - & - & + & ++ \\
\hline & AS3 & - & - & - & ++ & ++ \\
\hline & $\mathrm{AS} 4$ & - & - & + & + & + \\
\hline \multirow[t]{4}{*}{2 hours } & AS1 & - & - & - & + & ++ \\
\hline & $\mathrm{AS} 2$ & - & - & - & - & + \\
\hline & AS3 & - & - & - & + & ++ \\
\hline & $\mathrm{AS} 4$ & - & - & - & + & + \\
\hline \multirow[t]{4}{*}{3 hours } & $\mathrm{AS} 1$ & - & - & - & - & + \\
\hline & AS2 & - & - & - & - & + \\
\hline & AS3 & - & - & - & - & + \\
\hline & AS4 & - & - & - & - & - \\
\hline
\end{tabular}

\begin{tabular}{|c|c|c|c|c|}
\hline \multirow{2}{*}{\multicolumn{5}{|c|}{$\begin{array}{r}\text { The growth speed and survival ability of isolates: }(+++) \text { high; }(++) \text { moderate; }(+) \text { low; }(-) \text { isolates did not grow. } \\
\text { The plates were incubated at } 37^{\circ} \mathrm{C} \text { for } 1 \text { to } 5 \text { days. The }\end{array}$}} \\
\hline & & & & \\
\hline \multirow[b]{2}{*}{ Isolate Code } & \multicolumn{4}{|c|}{ Inhibition Zone $(\mathrm{mm}) \pm$ Standard Deviation $(\mathrm{SD})$} \\
\hline & E. coli & S. aureus & Positive Control & Negative Control \\
\hline AS1 & $11.17 \pm 0.29$ & 0 & & \\
\hline AS2 & 0 & $9.08 \pm 0.14$ & $38.33 \pm 2.02$ & 0 \\
\hline $\mathrm{AS} 3$ & $11.17 \pm 0.29$ & $11.3 \pm 0.58$ & & \\
\hline AS4 & $11.67 \pm 0.29$ & $8.33 \pm 0.76$ & & \\
\hline
\end{tabular}


formation of white precipitation around LAB colonies indicates the hydrolysis of bile salts by bile salts hydrolase (BSH) activity [28].

\subsection{Identification of Next-generation Probiotics}

The selected BAL isolates, which showed the best results on acid resistance, antibacterial activity, and ability to lower cholesterol, were selected. Identification included Gram staining [29], catalase test [30], and

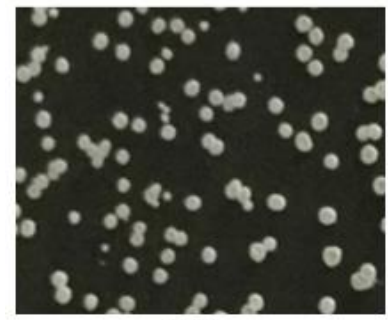

AS1

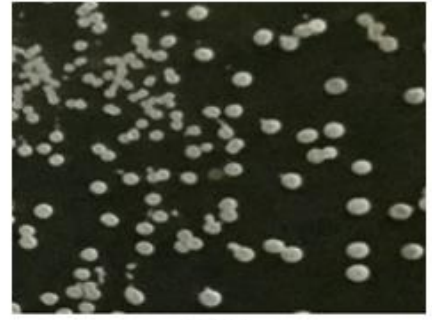

AS2

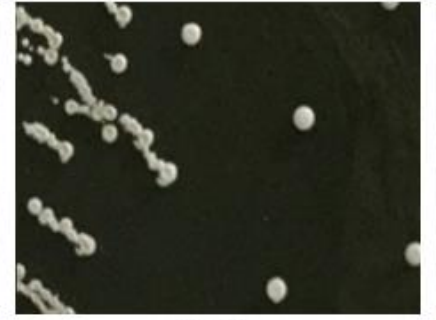

AS3

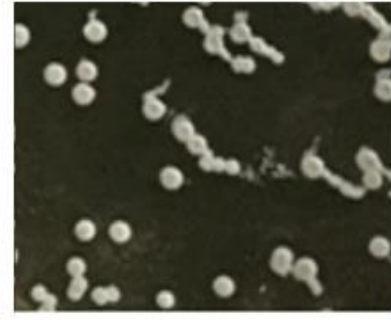

AS4

Figure 1. Precipitation of deoxycholic acids due to deconjugation of taurine-conjugated bile acids observed in isolate AS1, AS2, AS3, and AS4. The white precipitates around colonies indicates the BSH activity

molecular test using 16S rRNA gene marker. Catalase test was done to find out whether the isolates produced the catalase enzyme or not. Briefly, a small amount of each isolate was placed on a glass slide using a sterile wooden toothpick. Five percent of $\mathrm{H}_{2} \mathrm{O}_{2}$ was dropped onto the colony. The presence of an oxygen bubble on the tested bacteria indicated a positive result.

Molecular identification began with DNA extraction using Presto ${ }^{\mathrm{TM}}$ Mini gDNA Bacteria kit. The isolated DNA was amplified using PCR KOD FX Neo kit. The components of the PCR reaction included $5 \mu \mathrm{lddH} 2 \mathrm{O}$, $12.5 \mu \mathrm{l}$ PCR Buffer KOD FX neo, $5 \mu \mathrm{l}$ dNTPs, $0.5 \mu \mathrm{l}$ KOD FX Neo, $1 \mu$ l DNA template, $0.5 \mu$ primer $27 \mathrm{~F}$ (forward) dan $0.5 \mu \mathrm{l}$ primer $1492 \mathrm{R}$ (reverse). The condition of PCR reaction was initial denaturation at $95^{\circ} \mathrm{C}$ for $3 \mathrm{~min}$ ( 1 cycle), followed by 35 cycles of denaturation at $98^{\circ} \mathrm{C}$ for $15 \mathrm{sec}$, annealing at $52^{\circ} \mathrm{C}$ for 30 sec, elongation at $68^{\circ} \mathrm{C}$ for $45 \mathrm{sec}$, and held at $4^{\circ} \mathrm{C}$. The $16 \mathrm{~S}$ rRNA fragments generated from PCR were sequenced [31].

\subsection{Analysis of $16 \mathrm{~S}$ rRNA sequences}

The stepwise analysis of the 16S rRNA sequences was conducted following previous research [32]. DNA sequences were extracted from the chromatogram after removing 50 nucleotides at the beginning and end of the sequences containing the primers. The aligned contiguous consensus sequences were used for the homology search by BLAST software (http://blast.ncbi.nlm.nih.gov) algorithm at the National Center for Biotechnology Information (NCBI). The results were confirmed using Ez-Taxon database (https://www.ezbiocloud.net/) [33]. The reference

\section{RESULT AND DISCUSSION}

\subsection{Isolation of Lactic Acid Bacteria from Fermented Brine}

Four LAB with distinct colony characteristics were able to be isolated and purified from $10 \%$ Romaine lettuce fermented brine. The ability to withstand high salt concentration is one of the characteristics of LAB [35]. Each colony was coded as follows: isolate AS1, AS2, AS3 and AS4. The growth of the isolates on MRSA, which supplemented with $1 \% \mathrm{CaCO}_{3}$, produced clear zones surrounding the colonies. This indicated that the LAB produced organic acids, such as lactic acid and/or acetic acid. This clear zone was soluble calcium lactate as the result of a reaction between lactic acid produced by $\mathrm{LAB}$ and $\mathrm{CaCO}_{3}$ in the media.

\subsection{Acid Endurance}

To evaluate the acid endurance of isolated LAB, we compared the survival of four LAB isolates in an acidic environment $(\mathrm{pH} 3)$ for 3 hours. The results are presented in Table 1. The isolate AS4 had the highest survival rate. It started to grow on MRS agar after three days after being challenged on the acidic environment for 1 hour. After four days of incubation, AS3 started to grow. Only isolates AS1, AS2, and AS3 withstood the 3 hours challenge and grew on day 5 th.

A study showed that the longer the incubation time at low $\mathrm{pH}$, the ability to survive, and the speed of bacterial growth in MRSA media decreased [30]. It was 
because that acidic condition causes damage to the cell membranes and induces the releasing of intracellular components, resulting in the death of the cells. This implies that bacterial isolates that withstood the acid had resistance to membrane damage. However, because only a small amount of bacteria survived after being exposed to an acidic environment, the isolates needed a longer lag time to adapt to a new environment (MRS agar) and multiplied. Lactic acid bacteria can survive in the acidic environment because it has a mechanism to maintain $\mathrm{pH}$ conditions in its cells [36]. Some studies showed that some LAB isolated from fermented fruits and vegetables were resistant to acid [37, 38].

\subsection{Antibacterial Activity Assay}

One important criterion for $\mathrm{LAB}$ to be developed as NGP is antimicrobial activity. This activity is a natural defense of LAB towards potentially harmful bacteria. Therefore, four isolates were screened for their activity against indicator strains (E. coli and S. aureus subsp. aureus). The results are presented in Table 2. According to their abilities to inhibit bacterial indicators, the LAB strains with clear zones $<11 \mathrm{~mm}, 11-16 \mathrm{~mm}, 17-22 \mathrm{~mm}$ and $>23 \mathrm{~mm}$ were classified as negative (-), mild (+), strong (++), and very strong $(+++)$ inhibitors, respectively. The isolates AS1, AS3, and AS4 had a mild activity in inhibiting E. coli. The isolates AS3 had a mild activity, and AS2 and AS4 had no activity against $\mathrm{S}$. aureus. This finding shows that AS3 had a broad spectrum caused by its ability to inhibit E. coli and S. aureus.

The greater the inhibition zone, the more effective the isolates in inhibiting the growth of microorganisms. Even so, a small inhibition zone does not indicate that isolate is less effective, but its concentration has not reached an effective concentration to inhibit the growth of microorganisms [39]. A broad antibacterial spectrum is essential for probiotics [5]. Some study showed that LAB isolated from fermented vegetables had mild to strong antibacterial activity against indicator pathogens $[13,40,41,42]$.

\subsection{Cholesterol-owering Assay}

One mechanism for cholesterol removal by probiotics is the deconjugation of bile salts by bile-salt hydrolase (BSH). The LAB isolates were assayed in vitro for their BSH activities against taurodeoxycholic acids (TDCA). The ability of LAB to deconjugate bile salts demonstrates their potential to lower cholesterol. A qualitative method in evaluating the ability of the isolates to lower cholesterol was by spreading them onto MRS agar supplemented with $0.5 \%$ TDCA. The precipitations of deoxycholic acid were observed in all isolates after $48-72$ hours of incubation at $37^{\circ} \mathrm{C}$ (Fig. 1). Bile salt hydrolase (BSH) produced by LAB caused the release of taurine from taurine-conjugated bile salts and produced white precipitate of unconjugated bile salts (deoxycholic acid) [43].

The formation of a precipitate indicates that the isolates have $\mathrm{BSH}$ that can reduce cholesterol levels. The greater the precipitation formed, the higher the ability of these isolates to lower cholesterol. A research showed opaque white colonies produced by some intestinal bacteria from the genus Bifidobacterium [44]. Begley [19] explained that in the liver, primary bile acids (PBAs) are synthesized from cholesterol. Prior to secretion, PBAs are conjugated with either glycine or taurine. The peptide linkage of bile salts is hydrolysed by $\mathrm{BSH}$, resulting the removal of the amino acid group from the steroid core. The unconjugated bile salts will precipitate at low $\mathrm{pH}$. Lactic acid bacteria produced by kimchi fermentation was shown to have the capability to lower cholesterol [45]. The LAB isolated from fermented Brassica juncea pickle also had a cholesterollowering activity [46].

\subsection{Analysis of 16S rRNA Sequences}

Four discrete colonies were able to be separated from the media for purification and identification. Each was catalase-negative and Gram-negative with short rod-shaped morphology. One isolate (AS3) which showed the highest potential to be developed as NGP were identified molecularly using $16 \mathrm{~S}$ rRNA. BLAST search showed that isolate AS3 had $99.76 \%$ identity with Enterococcus faecium QU 50, while Ez-taxon database showed that AS3 had $99.65 \%$ similarity with E. durans NBRC 100479. Phylogenetic analysis by Maximum Likelihood method is shown in Fig. 2. The genetic distance is presented in Table 3, showing the number of base substitutions per site between sequences. The analysis was conducted using the Kimura 2-parameter model [47].

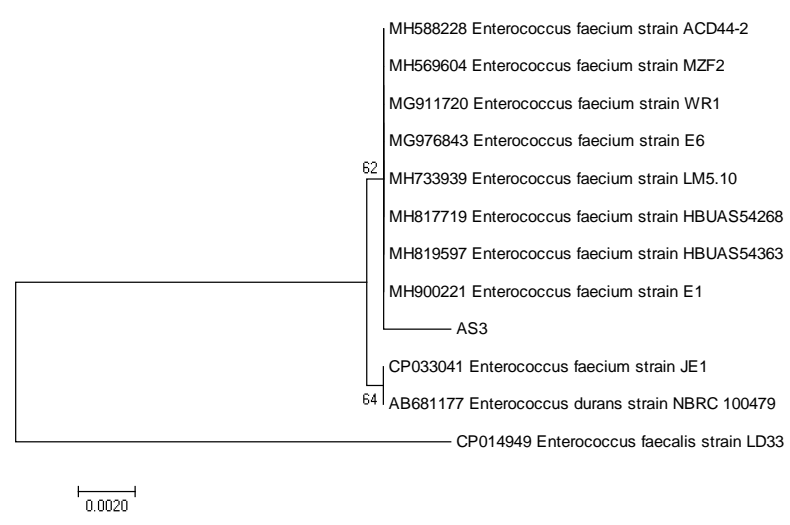

Figure 2. Molecular phylogenetic analysis inferred by using the Maximum Likelihood method based on the Kimura 2-parameter model (Kimura, 1980). Enterococcus faecalis was used as an outgroup. 
Analysis of phylogenetic showed that isolate AS3 is clustered with E. faecium except strain JEI which has $100 \%$ identity with $E$. durans. The genetic distance of AS3 and its allied E. faecium is 0.002 and 0.004 with $E$. faecium strain JE1 and E. durans NBRC 100479. This confirms that AS3 is E. faecium. The kinship relationship of each species can be measured from the size of the genetic distance. The less the value of the genetic distance between the two organisms, the closer is the relationship between them [48]. Enterococci are lactic acid bacteria (LAB), show tolerance to salts and acid, and involved in the traditional fermentation process [49]. Enterococcus faecium showed antibacterial activity [50], probably because of having bacteriocin as possessed by Enterococci in general [51]. This bacterium had also cholesterol-lowering activity [52] and survived in acidic conditions [53].
[2] Swain MR, Anandharaj M, Ray RC and Parveen R 2014 Biotechnol. Res. Int. 2014250424 doi: $10.1155 / 2014 / 250424$

[3] Özogul F and Hamed I 2018 Food Sci. Nut. 58(10) 1660-1670 doi:10.1080/10408398.2016.1277972

[4] Chang CJ, Lin TL, Tsai YL, Wu TR, Lai WF, Lu CC, and Lai HC 2019 J. Food \& Drugs Analysis (in press) doi: 10.1016/j.jfda.2018.12.011

[5] Fijan S 2016 IntechOpen doi:10.5772/63141

[6] Arief II, Betty SLJ, Astawan M, Kazuhito F and Arief BW 2015 Asian J. Animal Sci. 9(1) 25-36

[7] Tallapragada P, Ross SD, and Schmale DG 2011 Chaos 21(3) 033122 doi:10.1063/1.3624930

[8] Zhuang G, Liu XM, Zhang QX, Tian FW, Zhang H, Zhang HP and Chen W 2012 Clin. Lipidology

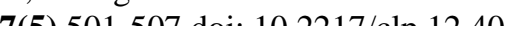

Table 3. Estimation of evolutionary divergence between sequences

\begin{tabular}{|c|c|c|c|c|c|c|c|c|c|c|c|c|c|}
\hline & & 1 & 2 & 3 & 4 & 5 & 6 & 7 & 8 & 9 & 10 & 11 & 12 \\
\hline 1 & AS3 & & & & & & & & & & & & \\
\hline 2 & CP033041 E. faecium JE1 & 0.004 & & & & & & & & & & & \\
\hline 3 & MH900221 E. faecium E1 & 0.002 & 0.001 & & & & & & & & & & \\
\hline 4 & MH819597 E. faecium HBUAS54363 & 0.002 & 0.001 & 0.000 & & & & & & & & & \\
\hline 5 & MH817719 E. faecium HBUAS54268 & 0.002 & 0.001 & 0.000 & 0.000 & & & & & & & & \\
\hline 6 & MH733939 E. faecium LM510 & 0.002 & 0.001 & 0.000 & 0.000 & 0.000 & & & & & & & \\
\hline 7 & MG976843 E. faeciumE6 & 0.002 & 0.001 & 0.000 & 0.000 & 0.000 & 0.000 & & & & & & \\
\hline 8 & MG911720 E. faecium WR1 & 0,002 & 0.001 & 0.000 & 0.000 & 0.000 & 0.000 & 0.000 & & & & & \\
\hline 9 & MH588228 E. faecium ACD44-2 & 0.002 & 0.001 & 0.000 & 0.000 & 0.000 & 0.000 & 0.000 & 0.000 & & & & \\
\hline 10 & MH569604 E. faecium MZF2 & 0.002 & 0.001 & 0.000 & 0.000 & 0.000 & 0.000 & 0.000 & 0.000 & 0.000 & & & \\
\hline 11 & CP014949 E. faecalis LD33 & 0.030 & 0.028 & 0.028 & 0.028 & 0.028 & 0.028 & 0.028 & 0.028 & 0.028 & 0.028 & & \\
\hline 12 & AB681177 E. durans NBRC 100479 & 0.004 & 0.000 & 0.001 & 0.001 & 0.001 & 0.001 & 0.001 & 0.001 & 0.001 & 0.001 & 0.028 & \\
\hline
\end{tabular}

\section{CONSLUSION}

This study suggests that LAB AS3 isolated from fermented brine product of Romaine lettuce can be developed further as NGP. It is because this isolate was able to withstand the acid environment ( $\mathrm{pH} 3)$, inhibits both E. coli and S. aureus, and had a cholesterollowering activity.

\section{ACKNOWLEDGMENTS}

This research was funded by Directorate General of Higher Education, Ministry of Research, Technology, and Higher Education of the Republic of Indonesia under the project "Excellent Basic Research of Higher Education (PDUPT)" the fiscal year 2019.

\section{REFERENCES}

[1] Juodeikiene G, Bartkeine E, Viskelis P, Urbonaviciene D, Eidukonyte D and Bobinas C 2012 Adv. App. Biotech doi: 10.5772/30692
[9] Nguyen TDT, Kang JH and Lee MS 2007 Int. J. Food Microbiol. 113(3) 358-361 doi:10.1016/j.ijfoodmicro.2006.08.015

[10] Belicová A, Mikulášová M and Dušinský R 2013 BioMed. Res. Int. Article ID 760298 doi:10.1155/2013/760298

[11] Karami S, Roayaei M, Hamzavi H, Bahmani M, Hassanzad-Azar H, Leila M and Rafieian-Kopaei M 2017 Int. J. Pharma Investig. 7 137-41 doi:10.4103/jphi.JPHI_8_17

[12] Mishra V, Shac C, Mokashe N, Chavan R, Yadav H and Prajapati J 2015 J. Agric. Food Chem. 63(14) 3615-26 doi:10.1021/jf506326t

[13] Wang CY, Lin PR, Ng CC and Shyu YT 2010 Anaerobe $\quad \mathbf{1 6 ( 6 )} \quad 578-585$ doi:10.1016/j.anaerobe.2010.10.003 
[14] Divyashri G, Krishna G, Muralidhara and Prapulla SG 2015 J. Med. Microb. 54 1527-1540 doi:10.1099/jmm.0.000184

[15] Kwak SH, Cho YM, Noh GM and Om AS 2014 J. Cancer Prev. $19 \quad 253-258$ doi:10.15430/JCP.2014.19.4.253

[16] Prosekov A, Dyshlyuk L, Milentyeva I, Sukhih S, Babich O, Ivanova S, Pavskyi V and Shishin M, Matskova L 2015 Integr. Mol. Med. 2(5) 295303 doi:15761/IMM.1000157

[17] Kaur A, Aurora M and Pandove G $2014 \mathrm{~J}$. Global Biosci. 3(3) 686-693

[18] Lahtinen S, Ouwehand AC, Salminen S and Wright AV 2011 Lactic Acid Bacteria: Microbiological and Functional Aspects (London: CRC Press)

[19] Begley M, Hill C and Gahan CG 2006 App. Env. Microb. 72(3) 1729-1738

[20] Guo Z, Liu XM, Zhang QX, Shen Z, Tian FW, Zhang H, Sun ZH, Zhang HP and Chen W 2011 Nutr. Metab. Cardiovas. Dis. 21 844-850 doi:10.1016/j.numecd.2011.04.008

[21] Breidt F, McFeeters RG, Perez-Diaz I and Le CH 2013 Food Microbiology: Fundamentals and Frontiers, 4th Ed (Washington DC: ASM Press) doi:10.1128/9781555818463.ch33

[22] Anandharaj M, Ray RC and Parveen R 2014 Biotechnol. Res. Int. 2014250424 doi: 10.1155/2014/250424

[23] Chang JH, Shim YY, Cha SK and Chee KM 2010 J. Appl. Microbiol. 109(1) 220-30 doi:10.1111/j.1365-2672.2009.04648.x

[24] Chen YS, Wu HC and Yanagida F 2010 Brazilian J. Microb. 41(4) 916-921 doi:10.1590/S1517-838220100004000010

[25] Du Toit M, Franz PAMC, Dicks TML, Schillinger U, Haberer P, Warlies B, Ahrens F and Holzapfel WH 1998 Int. J. Food Microbiol. 40 93-10 doi:10.1016/S0168-1605(98)00024-5

[26] Rammelsberg M and Radler F $1990 \mathrm{~J}$. Appl. Microbiol. 69(2) 177-184 doi: 10.1111/j.13652672.1990.tb01507.x.

[27] Zare Mirzaei E, Lashani E and Davoodabadi A 2018 Hyg. Infect. Control. 13 Doc01 doi:10.3205/dgkh000307.

[28] Gupta A and Sharma N 2017 J. Food Microbiol Saf. Hyg. 2(1) 119 doi:10.4172/24762059.1000119

[29] Gerhardt P, Murray RGE, Costilow RN, Nester EW, Wood WA, Krieg NR and Phillips
GB 1981 Manual of Methods for General Bacteriology (Washington DC: American Society for Microbiology)

[30] Bawole KV, Stella DU and Trina ET $2018 \mathrm{~J}$. MIPA UNSRAT Online 7(2) 20-23

[31] Gani MA, Talle TE and Fatimawali 2019 Pharmacon J. Ilmiah Farmasi 8(1) 57-64

[32] Tallei TE and Kolondam BJ 2015 Hayati J Biosci. 22(1) 41-47 doi:10.4308/hjb.22.1.4

[33] Yoon SH, Ha SM, Kwon S, Lim J, Kim Y, Seo $\mathrm{H}$ and Chun J 2017 Int. J. Syst. Evol. Microbiol. 67 1613-1617 doi:10.1099/ijsem.0.001755

[34] Kumar S, Stecher G and Tamura K 2016 Mol. Biol. $\quad$ Evol. $\quad 33(7) \quad 1870-1874$ doi:10.1093/molbev/msw054

[35] Gomes BC, Franco BDGM and Martinis ECPD 2010 Current research, technology and education topics in applied microbiology and microbial biotechnology (Spain :Formatex Research Center)

[36] Halim CN and Zubaidah E 2013 J. Pangan Argoind. 1(1) 129-137

[37] Randazzo CL, Restuccia C, Romano AD and Caggia C 2004 Int. J. Food Microbiol. 90(1) 914 doi:10.1016/S0168-1605(03)00159-4

[38] Higashikawa F, Noda M, Awaya T, Nomura K, Oku H and Sugiyama M 2010 Nutrition 26(4) 367-374 doi:10.1016/j.nut.2009.05.008

[39] Adam AA, Posangi J, Tumewu E, Tallei TE 2014 Dentire J. 3(2) 118-122

[40] Kazemipoor M, Radzi CWJWM, Begum K and Yaze I 2012 Archives Des Sci. 65(6) 10

[41] Delgado A, Brito D, Peres C, Noé-Arroyo F and Garrido-Fernández A 2005 Food Microb. 22(6) 521-528 doi: 10.1016/j.fm.2004.11.015

[42] Joshi VK, Sharma S and Rana NS 2006 Food Technol. Biotechnol. 44 435-439

[43] Kim GB, Brochet $\mathrm{M}$ and Lee BH 2005 Biotechnol. Lett. 27 817-822

[44] Jarocki P, Podleśny M, Glibowski $\mathrm{P}$ and Targoński Z 2014 PLoS ONE 9(12) e114379 doi:10.1371/journal.pone.0114379

[45] Choi IH, Noh JS, Han JS, Kim HJ, Han ES and Song YO 2013 J. Med. Food 16(3) 223-229 doi: 10.1089/jmf.2012.2563

[46] Chaiyasut C, Kesika P, Sirilun S, Peerajan S and Sivamaruthi BS 2018 J. App. Pharm. Sci. 8(4) 33-42 doi:10.7324/JAPS.2018.8405 
[47] Kimura M 1980 J. Mol. Evol. 16(2) 111-20 doi: 10.1007/BF01731581

[48] Tallei TE, Rembet RE, Pelealu JJ and Kolondam BJ 2016 Biosci. Res. 13(1) 01-07

[49] Foulquié Moreno MR, Sarantinopoulos P, Tsakalidou E and De Vuyst L 2006 Int. J. Food Microbiol. $\quad \mathbf{1 0 6}(1) \quad 1-24 \quad$ doi: 10.1016/j.ijfoodmicro.2005.06.026

[50] Hassanzadazar H, Ehsani A and Mardani K 2014 Summer 5(3) 169-175

[51] Hanchi H, Mottawea W, Sebei K and Hammami R 2018 Front Microbiol. 901791 doi:10.3389/fmicb.2018.01791

[52] Zhang F, Qiu L, Xu X, Liu Z, Zhan H, Tao X, Shah NP and Wei H 2017 J. Dairy Sci. 100 1618-1628 doi: $10.3168 /$ jds.2016-11870

[53] Khalkhali S and Mojgani N 2017 Iran J. Microbiol. 9(4) 224-233 